\title{
THE
}

\section{Roles of Carboxyl Groups in the Transmembrane Insertion of Peptides}

\author{
Francisco N. Barrera \\ Dhammika Weerakkody \\ University of Rhode Island \\ Michael Anderson \\ University of Rhode Island \\ Oleg A. Andreev \\ University of Rhode Island, andreev@uri.edu \\ Yana K. Reshetnyak \\ University of Rhode Island, reshetnyak@uri.edu \\ Follow this and additional works at: https://digitalcommons.uri.edu/phys_facpubs

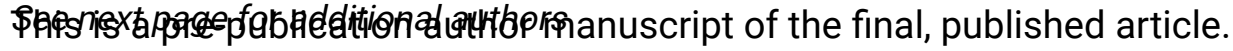 \\ Creative Commons License \\ (c) $($ ) $\ominus$
}

This work is licensed under a Creative Commons Attribution-Noncommercial-No Derivative Works 4.0 License.

\section{Citation/Publisher Attribution}

Barrera, F. N., Weerakkody, D., Anderson, M., Andreev, O. A., Reshetnyak, Y. K., \& Engelman, D. M. (2011). Roles of Carboxyl Groups in the Transmembrane Insertion of Peptides. Journal of Molecular Biology, 413(2), 359-371. doi: 10.1016/j.jmb.2011.08.010

Available at: https://doi.org/10.1016/j.jmb.2011.08.010

This Article is brought to you for free and open access by the Physics at DigitalCommons@URI. It has been accepted for inclusion in Physics Faculty Publications by an authorized administrator of DigitalCommons@URI. For more information, please contact digitalcommons-group@uri.edu. 


\section{Authors}

Francisco N. Barrera, Dhammika Weerakkody, Michael Anderson, Oleg A. Andreev, Yana K. Reshetnyak, and Donald M. Engelman

This article is available at DigitalCommons@URI: https://digitalcommons.uri.edu/phys_facpubs/311 


\title{
Roles of carboxyl groups in the transmembrane insertion of peptides
}

\author{
Francisco N. Barrera1, Dhammika Weerakkody², Michael Anderson², Oleg A. Andreev², \\ Yana K. Reshetnyak ${ }^{2}$, and Donald M. Engelman ${ }^{1, *}$ \\ ${ }^{1}$ Department of Molecular Biophysics and Biochemistry, Yale University, P.O. Box 208114, New \\ Haven, CT 06520 \\ ${ }^{2}$ Physics Department, University of Rhode Island, Kingston, RI, 02881, USA
}

\section{Abstract}

We have used the pHLIP ${ }^{\circledR}$ peptide to study the roles of carboxyl groups in transmembrane peptide insertion. The $\mathrm{pH}$ (low) insertion peptide (pHLIP) binds to the surface of a lipid bilayer as a disordered peptide at neutral $\mathrm{pH}$, and when the $\mathrm{pH}$ is lowered it inserts across the membrane to form a transmembrane helix. Peptide insertion is reversed when the $\mathrm{pH}$ is raised above the characteristic $\mathrm{pKa}$ (6.0). A key event facilitating the membrane insertion is the protonation of aspartic (Asp) and/or glutamic (Glu) acid residues, since at neutral $\mathrm{pH}$ their negatively charged side chains hinder membrane insertion. In order to gain mechanistic understanding, we studied the membrane insertion and exit of a series of pHLIP variants where the four Asp residues were sequentially mutated to nonacidic residues, including histidine (His). Our results show that the presence of His residues does not prevent the $\mathrm{pH}$-dependent peptide membrane insertion at $\sim \mathrm{pH} 4$ driven by the protonation of carboxyl groups at the inserting end of the peptide. A further $\mathrm{pH}$ drop leads to the protonation of His residues in the TM part of peptide, which induces peptide exit from the bilayer. We also find that the number of ionizable residues that undergo a change in protonation during membrane insertion correlates with the $\mathrm{pH}$-dependent insertion into and exit from the lipid bilayer, and that cooperativity increases with their number. We expect that our understanding will be used to improve the targeting of acidic diseased tissue by pHLIP peptides.

\section{Keywords}

membrane protein folding; pHLIP; $\mathrm{pH}$ trigger; carboxyl titration; transmembrane helix

\section{Introduction}

Extracellular acidification is a hallmark of different pathologies, including cancer, inflammation, ischemic stroke and atherosclerotic plaques. Acidosis might be a useful biomarker for diagnosis or treatment if means can be found to target tissue acidity. We have found that a peptide derived from the helix $\mathrm{C}$ of bacteriorhodopsin ${ }^{1}$, named $\mathrm{pHLIP}{ }^{\circledR}$ (for $\mathrm{pH}$ (Low) Insertion Peptide), is capable of targeting acidic tissues and inserting into the cell plasma membrane ${ }^{2}$.

\footnotetext{
(C) 2011 Elsevier Ltd. All rights reserved.

"Corresponding author. donald.engelman@yale.edu.
}

Publisher's Disclaimer: This is a PDF file of an unedited manuscript that has been accepted for publication. As a service to our customers we are providing this early version of the manuscript. The manuscript will undergo copyediting, typesetting, and review of the resulting proof before it is published in its final citable form. Please note that during the production process errors may be discovered which could affect the content, and all legal disclaimers that apply to the journal pertain. 
pHLIP is able to target mouse tumors in vivo with high specificity ${ }^{2}$, which opens the possibility of its use for cancer imaging. Additionally, pHLIP has a promising therapeutic potential, as it is able to translocate cell impermeable cargo molecules, such as organic dyes, peptides, peptide nucleic acids and toxins, across the plasma membrane into the cytoplasm of tumor cells ${ }^{2,3}$. pHLIP itself does not have obvious acute toxicity in cells ${ }^{3}$ or in mice ${ }^{2}$. pHLIP is monomeric at low concentrations, with a mostly unstructured conformation in neutral and basic solutions (state I). If lipid vesicles or membranes are present at neutral $\mathrm{pH}$, pHLIP binds to their external surfaces with an energy of 6-7 kcal $/ \mathrm{mol}$ (state II) ${ }^{4}$. In the membrane-attached state, pHLIP remains largely unstructured ${ }^{1}$. However, if the solution $\mathrm{pH}$ is lowered, pHLIP inserts to form a transmembrane (TM) alpha helix (state III). The insertion is fully reversible and unidirectional, with the C-terminus being translocated across the membrane ${ }^{3}$. The pKa of peptide insertion into lipid bilayers is 6.0 , and the energy difference between the attached and inserted states is $1.8 \mathrm{kcal} / \mathrm{mol}$ at $37^{\circ} \mathrm{C}^{4}$.

The pHLIP sequence is relatively rich in acidic residues (Table 1). At neutral $\mathrm{pH}$, the combined negative charges of these residues, together with the carboxy terminus, constitute a large energetic barrier for pHLIP insertion across the membrane. The estimated energetic cost of transfer of a single aspartic acid residue from water to the hydrophobic core of the membrane is unfavorable by $3.6 \mathrm{kcal} / \mathrm{mol}$ for the unprotonated (negatively charged) state, while for the protonated (non-charged) state it is only $0.4 \mathrm{kcal} / \mathrm{mol}^{5}$. Assuming $3.6 \mathrm{kcal} / \mathrm{mol}$ for each carboxyl group, simultaneously moving four charged Asp, one Glu and the carboxy terminus into the membrane would cost $21.6 \mathrm{kcal} / \mathrm{mol}$, and the peptide partitioning into the membrane at equilibrium would be about one part in $10^{16}$. Thus, for pHLIP to be able to insert into membranes, protonation of a large fraction of the acidic residues can be expected, and knowledge of the protonation pattern of the acidic residues of pHLIP is an essential part of understanding the molecular mechanism of the membrane insertion process for any peptide containing carboxyl groups. Two classes of carboxyl groups are of interest: those that remain buried in the membrane after pHLIP is inserted into membrane, and those that traverse the hydrophobic core of the membrane during insertion ${ }^{6}$. Accordingly, we have studied both the $\mathrm{pH}$-driven membrane insertion and the exit process for a series of peptides where the key aspartic acid residues are sequentially mutated.

\section{Results}

Previous studies in our laboratories revealed that sequence variations in the transmembrane region of pHLIP can disrupt the delicate balance that preserves its water solubility. For example, a simultaneous change of the two aspartic acid residues at positions 14 and 25 to the homologous glutamic acid (Asp14/25Glu) resulted in a loss of $\mathrm{pH}$-dependent membrane insertion due to aggregation of the peptide in aqueous solution ${ }^{7}$ (we have recently developed new pHLIP variants with several Glu residues, which preserve $\mathrm{pH}$-dependent properties, unpublished data). In order to reduce the likelihood that the introduced variations in the peptides used in this work could cause aggregation, we decided to follow a dual strategy to increase their water-solubility: (i) we added an Asp-tag to the N-terminus (the non-inserting end) to increase the number of charges in the molecule, which typically improves the solubility of hydrophobic peptides 8,9 . This resulted in the replacement of the $\mathrm{N}$-terminal sequence AAEQ with DDDED (Table 1); and (ii) we used the TANGO algorithm ${ }^{10}$ to define the region of the pHLIP sequence with the highest aggregation tendency, and found this to be the stretch from residue 21 to 30 (coinciding with the most hydrophobic region of the peptide). We then mutated Leu26 to Gly, which greatly reduced the predicted aggregation tendency.

We incorporated these modifications into a series of pHLIP variants, where four aspartic acid residues were sequentially mutated to non-acidic polar residues. The aspartic acid 
residues at the $\mathrm{C}$-terminus of the peptide that transitorily traverse the core of membrane upon insertion (Asp31 and Asp33) were replaced with polar, but uncharged asparagine residues. On the other hand, for the Asp residues that are located in the core of the membrane after insertion (in the positions 14 and 25), histidine was chosen as the replacement residue, as it is expected to be partially charged at neutral $\mathrm{pH}$, thus improving water-solubility, while being only slightly polar in its uncharged state (the transfer energies from water to the bilayer interior are 0.43 and $0.11 \mathrm{kcal} / \mathrm{mol}$ for the neutral forms of Asp and His $^{5}$, respectively), so that the insertion properties of pHLIP may not be altered. The peptides were named D0-D3 according to the number of aspartic acid residues present in the regions of interest (TM and C-terminus, as the positively charged $\mathrm{N}$-terminus is not expected to interact with the membrane). For the variants with three aspartic acids, two alternatives were studied, one that kept Asp14 (D3a peptide) and the other Asp25 (D3b peptide).

We conducted experiments to test the state of the variants in solution, where pHLIP is largely found as an unstructured monomer ${ }^{11}$. Sedimentation velocity experiments were conducted to determine the oligomerization state of the different peptide variants in aqueous buffer. Previous analysis of wt pHLIP (at $7 \mu \mathrm{M}$ in $10 \mathrm{mM}$ phosphate buffer, $100 \mathrm{mM} \mathrm{NaCl}$, $\mathrm{pH} 8)^{11}$ showed that pHLIP is mostly monomeric, but a small oligomer population is observed $(\sim 6 \%)$. We performed our sedimentation velocity experiments under the same conditions, but with no $\mathrm{NaCl}$ in the solution. For each peptide, a peak with a sedimentation coefficient of $0.72 \pm 0.12 \mathrm{~S}$ (Table 2 and Fig. 1), which corresponds to a molecular weight of $3.4 \pm 0.8 \mathrm{kDa}$, was observed. This is in agreement with the expected monomer mass of the different peptides: $4126 \mathrm{Da}$ for $\mathrm{wt}$ and $\sim 4300 \mathrm{Da}$ for the different variants, the differences being ascribed to shape effects from the extended peptide. In the case of D1 and D0 a minor peak was also observed, with a sedimentation coefficient of $3.3 \pm 0.3 \mathrm{~S}$. This component represents $5 \pm 2 \%$ of the total population, and its sedimentation coefficient corresponds to a molecular weight of $43 \mathrm{kDa}$ (roughly consistent with the presence of an octameric or decameric particle). Comparison of our results with the previous report for wt suggests that the presence of oligomers is reduced at lower ionic strength. For the particular case of the D1 and D0 peptides, they seem to have a slightly higher oligomerization tendency in solution, but they are still 95\% monomeric. Thus, our results suggest that all the peptide variants remain soluble and are essentially monomeric. For the rest of the experiments, we employed lower peptide concentrations $(1.5-5 \mu \mathrm{M})$ than that used for sedimentation analysis $(7 \mu \mathrm{M})$, and thus the level of oligomers present for D1 and D0 is expected to be lower.

Fluorescence spectra of the peptides in aqueous solution at neutral $\mathrm{pH}$ showed that in all cases the emission maximum is centered around 347-349 nm (Fig. 2, black lines and Table 2 , indicating that the two tryptophan residues of the peptides are largely exposed to aqueous solution, as in fully unfolded proteins, and consistent with the slightly low sedimentation coefficient. This finding represents an improvement over the previously studied Asp14/25Glu mutant peptide, where peptide aggregation shifts the emission maximum to $342 \mathrm{~nm}$ in buffer at $\mathrm{pH} 8^{7}$. A similar fluorescence maximum was also observed for the Asp14/25Asn mutant under the same conditions ${ }^{2}$. The presence of mostly unstructured species in aqueous solution for each of the studied peptides was confirmed by circular dichroism (CD) experiments, since the observed CD spectra were characterized by a minimum at $203 \mathrm{~nm}$ (Fig. 3, black lines), as observed for pHLIP in state I.

The two lipid-interacting states of the pHLIP variants were then examined: state II, where wt pHLIP is mostly unstructured and attached at the bilayer surface and state III, where wt pHLIP forms a TM helix at low $\mathrm{pH}^{1,6}$. Fluorescence experiments in the presence of POPC liposomes revealed that for the two D3 variants, the characteristic fluorescence signatures for states II and III were evident: (i) in the presence of liposomes at neutral $\mathrm{pH}$ (Fig. 2, blue 
lines), the fluorescence emission maxima of the peptides was slightly shifted from $348.7 \pm 1.0$ $\mathrm{nm}$ to $346.2 \pm 1.2 \mathrm{~nm}$, accompanied by a small fluorescence increase (Table 2); and (ii) when the $\mathrm{pH}$ was lowered to $\mathrm{pH} 4$, a large fluorescence increase and spectral blue shift to $336.2 \pm 1.1 \mathrm{~nm}$ occurred (red lines), which are typically observed when the Trp side chain is buried in the membrane hydrophobic core. To complement the fluorescence data, we performed circular dichroism experiments under the same conditions (Fig. 3). The CD signature of the pHLIP membrane insertion process consists of the appearance of the characteristic signals associated with the formation of alpha helix: minima at 208 and 222 $\mathrm{nm}$ and positive ellipticity at $190 \mathrm{~nm}$. Both D3 variants showed very similar spectral changes as it was observed for wt upon acidification. Thus we concluded that replacement of one of the Asp residues in the TM region of the peptide does not lead to the changes of the peptide ability to interact with the membrane in a pH-dependent manner.

The D2 variant, where both Asps are replaced by His residues, also demonstrates a pHdependent membrane interaction. However, the spectral pattern is slightly different than for wt and D3 variants: the fluorescence intensity of D2 in the presence of POPC decreases in the $\mathrm{pH}$ range 8-6 with no significant changes of the spectral maximum at $\mathrm{pH} 8-7$ and a small shift to lower wavelengths at pH6 (Supplementary Fig. S1). The amount of helical structure of D2 at neutral pH is slightly higher than wt and D3 (Fig. 2 and Table 2), while no change is seen in the $\mathrm{pH}$ range $8-6$. As an explanation we suggest that D2 partitions somewhat more deeply into the membrane lipid bilayer than wt and D3 at neutral pHs, since His residues are expected to be only partially charged at neutral $\mathrm{pHs}$, which enhances the hydrophobicity of the peptide TM and its affinity for the lipid bilayer. The decrease of fluorescence signal in the $\mathrm{pH}$ range $8-6$ might be attributed to the partial quenching of emission of at least one of the Trp residues by one of the partially protonated His residues. At the same time at neutral $\mathrm{pHs}$ the peptide $\mathrm{C}$-terminus containing four negative charges (2 Asp, 1 Glu and C-terminus) does not partition into the membrane, keeping the peptide at the membrane surface. A further drop of $\mathrm{pH}$ to 3-4 is associated with fluorescence spectral maximum blue shift, increase of fluorescence intensity (Fig. 2) and appearance of more pronounced negative band at $225 \mathrm{~nm}$ on CD spectra (Fig. 3), which is usually indication of peptide insertion into the bilayer ${ }^{1}$. Reduction of $\mathrm{pH}$ leads to the protonation of negatively charged groups at the $\mathrm{C}$-terminus, and peptide insertion into the membrane. At the same time, we expect that protonation of His residues at low $\mathrm{pH}$ should occur, which might lead to the peptide exit from the lipid bilayer or, alternatively, formation of a pore channel in the lipid bilayer, where positively charged His residues would be pointed toward the channel. Calcein encapsulation control experiments were performed that rule out the formation of pores in the membrane by the D2 and D3 peptides (Supplementary Fig. S2). Thus, most probably, the $\mathrm{pKa}$ for protonation of His when it is embedded in a lipid bilayer is shifted to very low $\mathrm{pHs}$. We carried out fluorescence $\mathrm{pH}$ titrations to compare the behavior of D2 and wt peptides at pHs lower than 3.5 (Supplementary Fig. S3). While no fluorescence change was detected for wt at acid $\mathrm{pH}$ values, we observed that an additional process was present for D2, with an apparent pKa of 2.5, characterized by a fluorescence decrease and a red-shift of the spectral maximum, which might be associated with peptide exit from the lipid bilayer.

To establish the orientation of each helix in the membrane we performed Oriented Circular Dichroism (OCD) measurements, in which the light beam is oriented perpendicular to the planes of a stack of oriented lipid bilayers containing the peptides of interest. Theoretical calculations and experimental data indicate that helices oriented with axes parallel to the membrane surface, perpendicular to the incident light, give distinctly different CD signals from those of helices oriented across the bilayer, parallel to the incident light ${ }^{12-14}$. In the range of 190-240 nm the peptide CD spectrum is dominated by the $\pi-\pi^{*}$ and $\mathrm{n}-\pi^{*}$ transitions ${ }^{15}$. The $\pi-\pi^{*}$ transition in a helix splits into three components, one of which gives rise to a negative Gaussian band near $205 \mathrm{~nm}$, with its electric transition dipole parallel to 
the helical axis. When the incident light propagates parallel to the helical axis, the electric field vector is orthogonal to the $205 \mathrm{~nm} \pi-\pi^{*}$ dipole transition and there is no interaction between the electromagnetic wave and the dipole, which leads to the disappearance of the negative band at $205 \mathrm{~nm}$ in a CD spectrum. Thus, when the supported bilayers are oriented perpendicular to the light propagation, and a helix with a transmembrane orientation will have a CD spectrum that contains a positive $190 \mathrm{~nm}$ and a negative $225 \mathrm{~nm}$ band. If the helix adopts a membrane-surface orientation on the supported bilayer, then all transitions are seen and the OCD spectrum is the same as for a peptide CD spectrum in solution, with randomly oriented helices. Our data clearly indicate that $\mathrm{D} 2$ adopts a TM orientation at $\mathrm{pH}$ 3.5-4.5, while increasing the $\mathrm{pH}$ leads to peptide exit and the appearance of a membranesurface orientation of the helix (Fig. 4). The OCD spectrum at $\mathrm{pH} 1.9$ does not correspond to a TM helix. Thus, we conclude that the pKa of both or at least one of the His residues is significantly shifted from $6.3-6.9^{16}$ to a lower value (2.5) due to their location at the bilayer interface in state II, emphasizing the important influence of bilayer surface properties on the $\mathrm{pKs}$ of dissociating groups in interacting peptides. A similar trend was previously observed for peptides that insert into membranes via the deprotonation of His residues ${ }^{17,18}$, although the magnitude of the pKa shift was smaller. However, large changes in $\mathrm{pKa}$ are typically observed when the side chains are in different environments, as the protonation of titrable amino acids depends on the dielectric properties of their environment ${ }^{19}$. A fitting example of large pKa changes is found in the native environment of pHLIP, bacteriorhodopsin, where Asp14 and Asp25 have pKa values of 7.5 and higher than 9, respectively ${ }^{20}$, significantly higher than the 3.7-4.0 pKa value found for fully solvated aspartic acid side chains ${ }^{16}$.

D1 has one less Asp residue at the C-terminus than D2. The slightly larger blue-shift of fluorescence emission (Fig. 2) and higher content of helicity observed in the presence of POPC at neutral pHs (Fig. 3) could be associated with an even deeper position of the peptide in the membrane. Fluorescence spectral blue shift and intensity increase, together with an increase in ellipticity at $222 \mathrm{~nm}$ occur upon acidification, which might indicate protonation of Asp33, Glu34 and C-terminus and peptide insertion into the lipid bilayer. The OCD spectrum obtained for D1 at pH3.3 (Fig. 4) does not show a clear TM orientation of the helix: some decrease of ellipticity at $205-225 \mathrm{~nm}$ is observed, which might indicate the existence of a mixture of TM and surface-parallel orientations of helices or the appearance of a significantly tilted TM helix. D0, in contrast to all other pHLIP variants described above, has a blue-shifted maximum of fluorescence emission (Fig. 2) at neutral pHs in the presence of POPC, with a high content of helical structure (Fig. 3). Virtually no changes of spectral signal occur for D0 upon acidification (Fig. 2 and 3). The OCD data primarily reveal a surface orientation of the helix at low pHs (Fig. 4), as expected for a peptide with no aspartic acids.

To study the magnitude and directionality of the membrane insertion of the peptides we used a biotin-avidin binding assay. A biotin moiety was attached to the C-terminus of each peptide. The level of binding to avidin was measured, and the protection of the biotin molecule from avidin interaction was used to assess the translocation of the peptide Cterminus into the liposome interior. The biotin moiety was linked to the C-terminal Cys of the peptides via a long, polar PEG linker. The linker has a double purpose. It facilitates biotin access to the avidin binding site, and more critically for our experiments, helps to delineate between an intra- and extra-liposomal location of the biotin, since the polarity of the moiety makes a location inside the hydrophobic region of the bilayer unlikely. The amount of biotin binding to avidin molecules present exclusively outside the liposomes was quantified (see Materials and Methods for details). We did not detect avidin binding to biotin for the $\mathrm{D} 2$ peptide at low $\mathrm{pH}$ (Fig. 5A) due to the biotin translocation across a membrane, which complements our data suggesting complete insertion of these peptides across the lipid bilayer, and confirms that the directionality of insertion is the same as for wt. 
Only partial and no translocation of biotin across the membrane were seen for D1 and D0, respectively (Fig. 5A), in agreement with our results indicating partial (or tilted) and no insertion into the lipid bilayer of D1 and D0, respectively. Additionally, the translocation of the biotin (which can be considered as a cargo) across the membrane does not appear to significantly hinder the membrane insertion of the peptides. This might be explained by its small size $(526 \mathrm{Da})$ and its moderate polarity $(\log \mathrm{P}=-1.4$; see Materials and Methods for details), which are both well within the range of cargo properties that pHLIP has been reported to effectively translocate ${ }^{21}$. However, as the biotin assay used here is responsive to changes in the level of binding to avidin present on the outside of the liposomes, we cannot rule out the possible influences of different processes, such as peptide aggregation, although we have no reason to suspect them.

How does the number of carboxyls affect the $\mathrm{pK}$ and cooperativity of insertion? We monitored the $\mathrm{pH}$-induced changes in the position of the fluorescence emission maximum of the peptides, which provides details about peptide insertion into the lipid bilayer, in the presence of POPC (Fig. 6). A plot of the positions of the spectral maxima follows a sigmoid behavior as a function of $\mathrm{pH}$, corresponding to the transition between the interfacial and inserted states for all variants (except for D0). Fitting the experimental data provides the two main parameters that describe the insertion process: the $\mathrm{pKa}$ and the cooperatively ( $\mathrm{m}$ parameter). The $\mathrm{pKa}$ of membrane insertion obtained for wt $\mathrm{pHLIP}$ is $5.94 \pm 0.09$, which is in an agreement with previous reports ${ }^{1,7}$. For the different variants, shifts of the pKa to lower values ( 5.2) were detected (Fig. 7A). The reason for this decrease is unclear, but it might be related to the lower number of aspartic residues or to the presence of histidines in the TM region of the pHLIP variants. We do not think that the N-terminal DDDED sequence will influence the pKas of the peptides in our study, since its polarity should preclude hydrophobic interaction with the lipid bilayer, and thus it is not expected to be involved in the insertion process. However, we cannot rule out that it might reduce the overall membrane affinity of the peptide. While the pKas for the variants changed very little, we observed a gradual decrease in the cooperativity of the insertion process (m parameter) for peptides with fewer Asp residues, as the titration occurred progressively over a wider $\mathrm{pH}$ range ( $\sim 1 \mathrm{pH}$ unit for wt, and $\sim 2 \mathrm{pH}$ units for D1) (Fig. 6 and $7 \mathrm{~b}$ ). Our data indicate that the cooperativity of insertion is linked to the number of protonatable residues. Cooperativity and pKa might also respond to the position of protonatable groups in the peptide sequences and their proximity to each other. When pHLIP is at the surface of the vesicle and the $\mathrm{pH}$ is lowered, the protonation of one Asp residue might facilitate the protonation of other protonatable residues, shifting their $\mathrm{pKa}$ values. The protonation of the first Asp residue might induce partial insertion of the peptide into the membrane. In this scenario, the protonation of the neighboring Asp residues would be energetically favored to shield the negative charge (i.e. the pKa value of the neighboring Asp is shifted to higher values in a more hydrophobic environment) and then a positive feedback would be established, triggering membrane insertion.

How does the number and location of Asp residues affect peptide exit from the membrane? The $\mathrm{CD}$ and fluorescence changes associated with wt pHLIP lipid insertion at acid $\mathrm{pH}$ are completely reversible ${ }^{11}$. Here we also followed changes of $\mathrm{CD}$ and fluorescence signals and reversibility of biotin translocation across the membrane. The ellipticity increase associated with each peptide insertion into the membrane was found to be essentially reversible for wt and D3b (Fig. 3, dashed blue lines overlap with continuous blue lines), while for D3a, D2 and D1 the reversibility was only partial. Since changes of the CD signal upon acidification for D2-D0 are less pronounced than for wt and D3, the reversibility of the D2-D0 membrane insertion were also assessed by changes of the fluorescence signal (Supplementary Fig. S4). It is interesting to note the different levels of reversibility of the two D3 peptides: the insertion process is significantly more reversible in D3b (90\%) than in D3a (70\%) (Fig. 5B), 
suggesting a non-equivalence of the two buried positions. An overall, linear relationship was observed between the number of aspartic acid residues that interact with the membrane and the degree of alpha helix formation reversibility (Fig. 5B). The results obtained for the reversibility of the biotin translocation (exit process) were also in agreement (Fig. 5B).

An important consideration in the interpretation of the exit data is the time course of equilibration of the $\mathrm{pH}$ inside the liposomes, so we encapsulated the membraneimpermeable fluorescent probe 5(6)-carboxy-2', $7^{\prime}$-dichlorofluorescein in POPC liposomes to follow the $\mathrm{pH}$ changes. The fluorescence of the probe is $\mathrm{pH}$-sensitive, with a pKa of 5.1. When we varied the $\mathrm{pH}$ of the solution outside the liposomes, the fluorescence of the encapsulated probe changed in a sigmoid fashion, with an apparent pKa of 5.05 (data not shown). A relatively high proton permeation through unilamellar POPC liposomes in the minute time-scale has been reported elsewhere ${ }^{22,23}$. On the other hand, our kinetics data suggest that the time of wt peptide exit (with $2 \mathrm{TM}$ and $4 \mathrm{C}$-terminal protonatable groups) is in the range of milliseconds ${ }^{6}$. Thus, peptides exit from the lipid bilayer much faster that the $\mathrm{pH}$ is completely equilibrated inside liposome, and most probably, C-terminal residues cross the membrane in their non-charged form. The question is why the reversibility of D3a, D2 and in some degree D1, is only partial. To provide an explanation, we take into account the location of the Asp residues. For the peptide exit from the lipid bilayer to take place, the deprotonation of Asp residues must energetically destabilize the inserted state. Destabilization of the inserted state is mainly caused by the charges resulting from deprotonation of groups deeply buried in the hydrophobic core of the membrane. Therefore, the exit of wt and D3b, which have two or one Asps in the hydrophobic core of the membrane, is fully reversible. The reason for the difference in peptide insertion reversibility for D3a and D3b might be related to the presence of an arginine residue at position 11. Accordingly, the deprotonation of Asp25 in D3b would strongly destabilize the membraneinserted state due to the presence of a negative charge in the hydrophobic core of the membrane, favoring the exit process. However, the negative charge of Asp14 in D3a might be forming a salt bridge with the neighboring side chain of Arg11, which would result in a weaker destabilization of the inserted state. Another potential explanation is an altered position of the TM domain, which was mentioned above. There is a possibility that the TM domain in variants is shifted toward the $\mathrm{C}$-terminal residues, leading to a greater exposure of the amino acid in position 14 (with His in D3a) to the aqueous environment and a shift to the hydrophobic core of amino acids at positions 31 and 33. As a result, the de-protonation of His14 in D3a might be associated with less destabilization of the helix than de-protonation of His 25 in D3b. The side chains of Asp31 and Asp33 most probably are interacting with the headgroup region of the bilayer. The destabilization energy associated with their deprotonation is not enough to cause a complete exit from the membrane. Our results suggest that the deprotonation of acidic residues located in the hydrophobic core of the membrane ensures complete exit of the peptide.

\section{Discussion}

We have previously observed that even conservative changes in the pHLIP sequence can lead to peptide aggregation in solution at neutral $\mathrm{pH}^{7}$. Our results show that all the peptides in this study are soluble in solution, being essentially monomeric (the addition of a D-tag at the $\mathrm{N}$-terminus and the L26G mutation appear to favor peptide solubility). Spectral data obtained with D3-D0 peptides indicate that the lower the number of negatively charged groups in the peptide sequence the deeper the peptide partitions into a lipid bilayer, and the greater the helicity. At the same time, TM orientation (at least for the D3-D2 peptides) requires protonation of the Asp/Glu residues and the terminal carboxyl group at the Cterminus, which can readily go across a membrane in its non-charged form. We confirmed our previous finding ${ }^{2}$ suggesting that transmembrane Asp residues are not essential for 
peptide insertion. Interestingly, we have observed here that membrane insertion upon acidification occurs in our peptides in the presence of two His residues in the predicted TM region. Histidines have been used in the past to drive the insertion of peptides into membranes at neutral $\mathrm{pHs}^{17-18}$. However, in these examples, acidic residues were completely absent in the sequence. For the peptides described in this paper the establishment of states II and III is driven by acidic residues. Since the protonated (charged) state of the side chains of His 14 and His 25 in the hydrophobic core of the membrane would be energetically very unfavorable, in the peptides their pKa values are expected to shift to lower values in the membrane-inserted state (favoring the unprotonated state). Further acidification eventually causes their protonation, resulting in a strong destabilization of the inserted TM helix and peptide exit. We cannot rule out that the diminished membrane insertion of the D1 and D0 peptides might be influenced by the hydrophobicity change concomitant to the Asp to Asn mutations at the C-terminus. The free energy of membrane transfer of the Asn side chain is $0.42 \mathrm{kcal} / \mathrm{mol}$, which is a less favorable value than the free energy of transfer of the neutral state of Asp, $-0.07 \mathrm{kcal} / \mathrm{mol}^{5}$, and thus the membrane translocation of the $\mathrm{C}$-terminus would be less favorable. A similar effect might occur in the insertion reversibility of D1.

We conclude that in order to preserve the $\mathrm{pH}$-dependent ability of the pHLIP peptide to interact with the membrane, protonation of negatively charged residues located in the TM or the C-terminal inserting end must occur. These residues act as switches for pHLIP membrane insertion, as the negative charges of their side chains block membrane insertion. Acidification causes the protonation of these side chains, resulting in an increase in the overall hydrophobicity of the peptide, which leads to the TM helix formation to shield the hydrophobic residues of pHLIP from water molecules. When the $\mathrm{pH}$ is raised to near neutrality, the negatively charged state of the carboxyl groups is again favored, decreasing the peptide hydrophobicity and resulting in exit from the transmembrane position. Peptide exit from the lipid bilayer is completed when deprotonation of Asp/Glu residues located in hydrophobic core of the membrane occurs and the TM helix is destabilized.

The knowledge gained from our experiments can be used as a guide to improve the imaging and therapeutic properties of pHLIP. For the specific case of tumor targeting, the pHLIP insertion characteristics should be finely tuned to exploit the low extracellular $\mathrm{pH}\left(\mathrm{pH}_{\mathrm{e}}\right)$ of tumors. Tumor targeting by wt pHLIP conjugated to a $\mathrm{Cu}^{64}$-DOTA chelate for PET (positron emission tomography) imaging correlates with the extracellular $\mathrm{pH}$ of tumors, where the contrast index was higher for $\mathrm{LNCaP}$ tumors $\left(\mathrm{pH}_{\mathrm{e}}=6.78 \pm 0.29\right)$, than for PC-3 tumors $\left(\mathrm{pH}_{\mathrm{e}}=7.23 \pm 0.10^{24}\right)$. Thus, pHLIP variants where Asp14/25 were replaced by Glu, with a higher $\mathrm{pKa}(\mathrm{pKa}=6.5)^{7}$, might be more effective for targeting of tumors with higher values of extracellular $\mathrm{pH}$. Our present results suggest that the number of Asp residues in the TM region can also modulate the $\mathrm{pKa}$ value. Thus, a peptide containing an extra Asp in the $\mathrm{TM}$ region might have a higher $\mathrm{pKa}$, and be directed to tumors more effectively. Another important factor to be considered is the broadness of the $\mathrm{pH}$-transition of the peptide, which is dictated by the cooperativity of the transition. On the one hand, for the case where the peptide $\mathrm{pKa}$ is lower than the tumor $\mathrm{pH}_{\mathrm{e}}$, but the transition is broad ( $\mathrm{m}$ value is low), a significant part of the $\mathrm{pH}$-transition could intercept with the $\mathrm{pH}_{\mathrm{e}}$ value, resulting in a significant pHLIP tumor insertion. However, such a scenario will lead to more accumulation in healthy tissue as well. Since it is usually desirable to have a high tumor/organ ratio, so an insertion transition of high cooperativity might be best. This would ensure a greater differentiation between the amount of inserted and non-inserted peptides over a narrow range of $\mathrm{pHs}$, favoring selective tumor targeting, since the difference in $\mathrm{pH}$ between normal and cancerous tissue may be only $0.5-0.7$ units. However, we must bear in mind that the measured $\mathrm{pH}_{\mathrm{e}}$ provides an indication of the average acidity outside the cell for a given tumor and can vary between different tumor regions. Further, $\mathrm{pH}_{\mathrm{e}}$ may not reflect the 
precise $\mathrm{pH}$ on the exterior surfaces of the cells, since the cells pump protons to the extracellular medium, and the delta $\mathrm{pH}$ will lead to proton accumulation at the membrane surface $^{25}$. Another feature that is expected to shift the equilibrium toward the membrane inserted form is the presence of Asp/Glu residues at the C-terminus of the peptide. After being translocated across the plasma membrane into the cytoplasm, where the $\mathrm{pH}$ is neutral, these groups would be de-protonated. Since the translocation of charges across membranes is unfavorable, the inserted form would be stabilized.

The pHLIP has promise as a means of targeting cells in acidic tissues and delivering agents for therapy and imaging. At the same time, we are learning more about the binding and insertion of peptides at a membrane surface. Here we have shown that variation of the positions and number of carboxyl group titrations modulates the $\mathrm{pK}$ and cooperativity of insertion.

\section{Materials and methods}

\section{Peptide synthesis and assessment of monomeric state}

Peptides were made by solid-phase synthesis using standard 9-fluorenylmethyloxycarbonyl chemistry at the W.M. Keck Foundation Biotechnology Resource at Yale University (New Haven, CT) and purified by reverse phase chromatography (C18 column, using a water/ acetonitrile gradient in $0.01 \%$ trifluoroacetic acid). Purity was checked by MALDI-TOF mass spectrometry. Peptides were quantified by absorbance spectroscopy, using a molar extinction coefficient of $13940 \mathrm{M}^{-1} \mathrm{~cm}^{-1}$. Some peptides contain a single Cys residue in the $\mathrm{C}$-terminus, and thus have the potential to form intermolecular disulfide bonds, leading to the formation of dimers. To rule out the possibility that this might be occurring in our experimental conditions, we ran HPLC on peptide samples incubated (at room temperature for $3 \mathrm{~h}$ ) at concentrations higher than those used in our experiments and in the absence and presence of POPC. No dimer band could be detected, and concentrations in the range of 0.1 $\mathrm{mM}$ peptide and $\mathrm{ON}$ incubation were required to detect a significant amount of dimer $(\sim 10$ $\%)$. Peptides described in Table 1 were used, except for some experiments with D2-D0, where a Cys-less version was employed (similar results were obtained for both results; data not shown).

\section{Analytical ultracentrifugation}

Sedimentation velocity experiments were performed at $25^{\circ} \mathrm{C}$ in a Beckman Optima XL-I at $35.000 \mathrm{rpm}$. Peptides were dissolved in $5 \mathrm{mM}$ phosphate buffer, $\mathrm{pH} 8$, at a concentration of $7 \mu \mathrm{M}$ after one hour incubation at root temperature. Absorbance at $280 \mathrm{~nm}$ was used to monitor the centrifugation, and analysis was performed using SEDFIT $^{26}$.

\section{Liposome preparation}

The required amount of chloroform-dissolved POPC (1-palmitoyl-2-oleoyl-sn-glycero-3phosphocholine) (Avanti Polar Lipids) was placed in a glass tube and dried with argon and then held under vacuum overnight. The dried film was resuspended in water or $10 \mathrm{mM}$ phosphate buffer $\mathrm{pH} 8$ and vortexed. Extrusion to make unilamellar vesicles was performed using a Mini-Extruder (Avanti Polar Lipids), with Nuclepore polycarbonate membranes of 0.1 or $0.05 \mu \mathrm{m}$ pore sizes (Whatman). Depending on the lipid concentration, 15-25 extrusion steps were performed to obtain the final large unilamellar vesicles.

\section{Fluorescence spectroscopy}

Peptides were dissolved in 5 or $10 \mathrm{mM}$ phosphate buffer, $\mathrm{pH} 8$, and incubated with POPC vesicles prepared in water, resulting in a molar lipid to peptide ratio of 250:1. The incubation time with POPC liposomes was varied from 90 min to 18 hours. The $\mathrm{pH}$ of the 
samples was adjusted with a $10 \mathrm{mM}$ concentration of the following buffers for the indicated pH ranges: $\mathrm{H}_{3} \mathrm{PO}_{4}$, $\mathrm{pH} 1.0-3.5$; sodium acetate, $\mathrm{pH} 3.5-5.5 ; \mathrm{Na}_{2} \mathrm{HPO}_{4} / \mathrm{NaH}_{2} \mathrm{PO}_{4}$, $\mathrm{pH}$ 5.58.0; sodium borate, $\mathrm{pH} 8.0-10.5$ or by addition of concentrated $\mathrm{HCl}$. The final peptide concentration was varied from 1.5 to $5 \mu \mathrm{M}$ in different experiments. Emission spectra were measured in a SLM-Aminco 8000C and PC2 ISS spectrofluorimeters at room temperature (controlled temperature) with excitation at $295 \mathrm{~nm}$. The appropriate blanks were subtracted in all cases.

For the determination of spectral maxima we used the FCAT mode of the PFAST software, which fits the experimental spectra to log-normal components ${ }^{27,28}$. The spectral maxima values for each point of the $\mathrm{pH}$ curve were plotted, and analyzed according to ${ }^{29}$ :

$$
F=\frac{\left(F_{a}+F_{b} 10^{m(p H-p K a)}\right)}{\left(1+10^{m(p H-p K a)}\right)}
$$

(Equation 1)

where $F_{a}=\left(\mathrm{f}_{A}+\mathrm{S}_{A} \mathrm{pH}\right)$ and $F_{b}=\left(\mathrm{f}_{B}+\mathrm{S}_{B} \mathrm{pH}\right) ; \mathrm{f}_{A}$ and $\mathrm{f}_{B}$ are the spectral maxima for the acid and basic forms, respectively, and $\mathrm{S}_{A}$ and $\mathrm{S}_{B}$ are the slopes of the acid and basic baselines, $\mathrm{m}$ is the cooperativity parameter. Fitting by nonlinear least squares analysis was carried out with Origin.

\section{Circular Dichroism}

Samples were prepared as in the fluorescence experiments, but the final molar lipid to peptide ratio was 300:1, with a final peptide concentration varied from 2 to $5 \mu \mathrm{M}$. CD spectra were recorded in a Jasco J-810 and MOS450 Biologic spectropolarimeters interfaced with a Peltier system. Spectra were recorded at $25^{\circ} \mathrm{C}$ using 2 or $5 \mathrm{~mm}$ cuvettes, the scan rate was $50 \mathrm{~nm} / \mathrm{min}$ and 10-30 averaging steps were performed. Raw data was converted to mean residue ellipticity (MRE) according to ${ }^{30}$ :

$$
[\Theta]=\Theta /(101 \mathrm{c} \mathrm{N})
$$

where $\Theta$ is the measured ellipticity, 1 is the pathlength of the cell, $\mathrm{c}$ is the protein concentration, and $\mathrm{N}$ is the number of amino acids.

For the study of membrane attachment, insertion and its reversibility, the typical procedure was as follows: samples were incubated with POPC vesicles at $\mathrm{pH} 8$ for 90 minutes and spectra recorded; then the $\mathrm{pH}$ was lowered to 4.0 and after 30 min measurements were performed. Finally, the $\mathrm{pH}$ of the sample was increased with sodium borate buffer, $\mathrm{pH} 10.2$ to a final $\mathrm{pH}$ of 7.5 and after 30,90 minutes and 24 hours spectra were recorded, and similar results were obtained in all cases. The degree of reversibility was established from the recovery of the signal at $222 \mathrm{~nm}$. The final buffer concentration for the different experiments was in the 3-15 mM range. Appropriate blanks were subtracted in all cases.

\section{OCD measurements}

For oriented circular dichroism measurements, supported bilayers were prepared on quartz slides with spacers of $0.2 \mathrm{~mm}$ thickness on one side and with a special polish for far UV measurements (Starna). Slides were cleaned by sonication for $10 \mathrm{~min}$ in cuvette cleaner solution (Decon Contrad70, 5\% in water), 2-propanol, acetone, 2-propanol and rinsed with deionized water. Then the slides were immersed in a mixture of concentrated sulfuric acid and hydrogen peroxide (ratio 3:1) for 5-10 min to completely remove any remaining organic material form the slides. Slides were then thoroughly rinsed with and stored in deionized water (Milli-Q purified water kept at $25^{\circ} \mathrm{C}$ ). A POPC lipid monolayer was deposited on a 
quartz substrate by the Langmuir-Blodgett (LB) method using a KSV minitrough. For the LB deposition, a cleaned slide was vertically immersed into the clean subphase (Milli-Q purified water kept at $25^{\circ} \mathrm{C}$ ) of a Langmuir-Blodgett trough. A POPC lipid solution in chloroform was spread on the subphase and chloroform allowed to evaporate for about 30 $\mathrm{min}$, followed by monolayer compression to $32 \mathrm{mN} / \mathrm{m}$. The first layer was deposited by retrieving the slide from the subphase at a rate of $15 \mathrm{~mm} / \mathrm{min}$. The second layer of the bilayer was created by fusion. For this step, the monolayer on the slide was incubated with a solution of POPC vesicles ( $50 \mathrm{~nm}$ in diameter obtained by extrusion) mixed with peptide solution at the required $\mathrm{pH}(0.5 \mathrm{mM}$ POPC and $10 \mu \mathrm{M}$ peptide). The fusion occurred for about 6 hours in $100 \%$ humidity condition. Then, excess vesicles were carefully removed and the slides were stacked to make a pile while filling up the spaces between them with a peptide solution $(5 \mu \mathrm{M})$ at the required $\mathrm{pH}$. The bilayers with the peptide solution were allowed to equilibrate for about 6 hours. Measurements were taken at 3 steps during the process: when the monolayers were incubated with an excess of liposomes, soon after the spaces between bilayers were filled with the peptide solution, and 6 hours after the second measurement. 14 slides ( 28 bilayers) were assembled and the OCD spectrum was recorded on a MOS-450 spectrometer with $2 \mathrm{~s}$ sampling time.

\section{Biotin translocation assay}

The HABA dye (4'-hydroxyazobenzene-2-carboxylic acid) binds to avidin with a 1 to 1 stoichiometry, and it absorbs at $510 \mathrm{~nm}$ only in the avidin-bound state. This interaction is strongly displaced by the binding of biotin to avidin, resulting in a quantitative reduction in HABA absorbance. This property was used to probe the location of the C-terminus of different peptides with regard to the liposome (inside or outside) (method modified from ${ }^{31}$ ). The C-terminus of each of the peptide variants was labeled with biotin (see below). The rationale for the assay is that $\mathrm{pH}$-driven insertion of the $\mathrm{C}$-terminus would result in biotin translocation inside the liposome, causing shielding of the biotin from the medium outside the liposome, where a preformed HABA/avidin complex (Thermo Scientific) is added. If the biotin is inside the liposome, no change in absorbance is expected. On the other hand, if pHLIP lies at the exterior surface of the liposome, the C-terminal biotin would be accessible to the solution outside the liposome (as the biotin group is polar, it is expected not to be protected by the membrane), and would be able to bind to avidin and displace the HABA/ avidin complex, with a consequent reduction in absorbance at $510 \mathrm{~nm}$. Liposomes were prepared in $150 \mathrm{mM} \mathrm{NaCl}$, and the ionic strength was carefully maintained during all steps to avoid liposome osmotic shock. Biotin-labeled peptides were incubated in the presence of $\mathrm{POPC}$ at $\mathrm{pH} 8$ for $2 \mathrm{~h}$ at room temperature (150:1 lipid to peptide ratio). For studies of Cterminal translocation, acetate buffer was added to the samples, resulting in a final $\mathrm{pH}$ of 4.3 prior to 1 hour incubation with the peptide. The HABA/avidin complex was added to the solution only after the final conditions were established. The final peptide concentration for the measurement conditions was $3 \mu \mathrm{M}$. To determine the reversibility of the biotin translocation, the $\mathrm{pH}$ was increased by the addition of $10 \mathrm{mM}$ sodium borate buffer, $\mathrm{pH}$ 10.2 , to give a final $\mathrm{pH}$ of 7.4. Absorbance was measured after 1 hour incubation. To quantitate the level of reversibility, the recovery of absorbance obtained for pHLIP labeled with biotin at its C-terminus was taken as $100 \%$ reversibility, and that of pHLIP labeled at its $\mathrm{N}$-terminus was taken as $0 \%$.

Peptides were labeled at the C-terminal Cys residues using the membrane-impermeable compound maleimide- $\mathrm{PEG}_{2}$-biotin (Thermo Scientific), which has a long polar spacer arm of $29.1 \AA$ to allow adequate biotin binding to avidin. The synthesis reaction was performed in $10 \mathrm{mM}$ phosphate buffer, $\mathrm{pH} 7.5$ (overnight incubation at $4{ }^{\circ} \mathrm{C}$ ). Reaction products were purified by HPLC, and the mass of the biotin-labeled peptides checked by MALDI-TOF mass spectrometry. The octanol/water partition coefficient of maleimide- $\mathrm{PEG}_{2}$-biotin was 
determined experimentally by measuring the absorbance at $300 \mathrm{~nm}$ in the aqueous and octanol (previously pre-equilibrated with water) phases after a $2 \mathrm{~h}$ vortexing. A $\log \mathrm{P}$ value of $-1.07 \pm 0.02$ was obtained. As this value does not take into account the chemical changes of the crosslinking reaction (formation of a thioether bond between the maleimide moiety and the Cys side chain), the QikProp 3.0 software was employed to predict the $\log$ P value of the reacted form, resulting in a value of -1.4 , which is in the range of molecules that can be translocated by $\mathrm{pHLIP}^{21}$.

\section{Supplementary Material}

Refer to Web version on PubMed Central for supplementary material.

\section{Acknowledgments}

The authors are thankful to Miriam Alonso, Ming An, Justin Fendos (Yale University) and José Luis Neira (Universidad Miguel Hernández) for stimulating discussions and insightful comments on the manuscript.

DME was supported by National Institutes of Health grant GM073857-04. OAA, DME and YKR were supported by National Institutes of Health grant CA133890-03. FNB was recipient of a postdoctoral fellowship from the Fundación Alfonso Martín Escudero.

\section{Abbreviations}

$\begin{array}{ll}\text { CD } & \text { circular dichroism } \\ \text { HPLC } & \text { high performance liquid chromatography } \\ \text { MALDI-TOF } & \text { Matrix-assisted laser desorption/ionization-time of flight } \\ \text { OCD } & \text { oriented circular dichroism } \\ \text { POPC } & \text { 1-palmitoyl-2-oleoyl-sn-glycero-3-phosphocholine } \\ \text { TM } & \text { transmembrane }\end{array}$

\section{References}

1. Hunt JF, Rath P, Rothschild KJ, Engelman DM. Spontaneous, pH-dependent membrane insertion of a transbilayer alpha-helix. Biochemistry. 1997; 36:15177-15192. [PubMed: 9398245]

2. Andreev OA, Dupuy AD, Segala M, Sandugu S, Serra DA, Chichester CO, Engelman DM, Reshetnyak YK. Mechanism and uses of a membrane peptide that targets tumors and other acidic tissues in vivo. Proc Natl Acad Sci U S A. 2007; 104:7893-7898. [PubMed: 17483464]

3. Reshetnyak YK, Andreev OA, Lehnert U, Engelman DM. Translocation of molecules into cells by pH-dependent insertion of a transmembrane helix. Proc Natl Acad Sci U S A. 2006; 103:64606465. [PubMed: 16608910]

4. Reshetnyak YK, Andreev OA, Segala M, Markin VS, Engelman DM. Energetics of peptide (pHLIP) binding to and folding across a lipid bilayer membrane. Proc Natl Acad Sci U S A. 2008; 105(40): 15340-5. [PubMed: 18829441]

5. White SH, Wimley WC. Membrane protein folding and stability;Physical principles. Annu Rev Biophys Biomol Struct. 1999; 28:319-365. [PubMed: 10410805]

6. Andreev OA, Karabadzhak AG, Weerakkody D, Andreev GO, Engelman DM, Reshetnyak YK. pH (low) insertion peptide (pHLIP) inserts across a lipid bilayer as a helix and exits by a different path. Proc Natl Acad Sci U S A. 2010; 107:4081-4086. [PubMed: 20160113]

7. Musial-Siwek M, Karabadzhak A, Andreev OA, Reshetnyak YK, Engelman DM. Tuning the insertion properties of pHLIP. Biochim Biophys Acta. 2009; 1798(6):1041-6. [PubMed: 19766589]

8. Melnyk RA, Partridge AW, Yip J, Wu Y, Goto NK, Deber C. Polar residue tagging of transmembrane peptides. Biopolymers. 2003; 71(6):675-85. [PubMed: 14991677] 
9. Cunningham F, Deber CM. Optimizing synthesis and expression of transmembrane peptides and proteins. Methods. 2007; 41:370-380. [PubMed: 17367709]

10. Fernandez-Escamilla AM, Rousseau F, Schymkowitz J, Serrano L. Prediction of sequencedependent and mutational effects on the aggregation of peptides and proteins. Nat Biotechnol. 2004; 22:1302-1306. [PubMed: 15361882]

11. Reshetnyak YK, Segala M, Andreev OA, Engelman DM. A monomeric membrane peptide that lives in three worlds: in solution, attached to, and inserted across lipid bilayers. Biophys J. 2007; (7):2363-72. [PubMed: 17557792]

12. Wu Y, Huang HW, Olah GA. Method of oriented circular dichroism. Biophys J. 1990; 57:797806. [PubMed: 2344464]

13. Merzlyakov M, Li E, Hristova K. Directed assembly of surface-supported bilayers with transmembrane helices. Langmuir. 2006; 31:1247-53. [PubMed: 16430290]

14. Kiessling V, Tamm LK. Measuring distances in supported bilayers by fluorescence interferencecontrast microscopy: polymer supports and SNARE proteins. Biophys J. 2003; 84:408-18. [PubMed: 12524294]

15. Woody, RW. Circular dichroism of peptides. In: Udenfriend, S.; Meienhofler, J., editors. The Peptides. Academic Press; New York: 1985. p. 15-114.

16. Pace CN, Grimsley GR, Scholtz JM. Protein ionizable groups: pK values and their contribution to protein stability and solubility. J Biol Chem. 2009; 284:13285-13289. [PubMed: 19164280]

17. Bechinger B. Towards membrane protein design: $\mathrm{pH}$-sensitive topology of histidine-containing polypeptides. J Mol Biol. 1996; 263:768-775. [PubMed: 8947574]

18. Ladokhin AS, White SH. Interfacial folding and membrane insertion of a designed helical peptide. Biochemistry. 2004; 43 (19):5782-91. [PubMed: 15134452]

19. Harms MJ, Castaneda CA, Schlessman JL, Sue GR, Isom DG, Cannon BR, Garcia-Moreno EB. The $\mathrm{pK}$ (a) values of acidic and basic residues buried at the same internal location in a protein are governed by different factors. J Mol Biol. 2009; 389:34-47. [PubMed: 19324049]

20. Lanyi JK. Proton transfers in the bacteriorhodopsin photocycle. Biochim Biophys Acta. 2006; 1757:1012-1018. [PubMed: 16376293]

21. Thevenin D, An M, Engelman DM. pHLIP-mediated translocation of membrane-impermeable molecules into cells. Chem Biol. 2009; 16:754-762. [PubMed: 19635412]

22. Kuyper CL, Kuo JS, Mutch SA, Chiu DT. Proton permeation into single vesicles occurs via a sequential two-step mechanism and is heterogeneous. J Am Chem Soc. 2006; 128(10):3233-40. [PubMed: 16522104]

23. Deamer DW, Nichols JW. Proton flux mechanisms in model and biological membranes. J Membr Biol. 1989; 107(2):91-103. [PubMed: 2469801]

24. Vavere AL, Biddlecombe GB, Spees WM, Garbow JR, Wijesinghe D, Andreev OA, Engelman DM, Reshetnyak YK, Lewis JS. A novel technology for the imaging of acidic prostate tumors by positron emission tomography. Cancer Res. 2009; 69:4510-4516. [PubMed: 19417132]

25. Bränden M, Sanden T, Brzezinski P, Widengren J. Localized proton microcircuits at the biological membrane-water interface. Proc Natl Acad Sci U S A. 2006; 103:19766-19770. [PubMed: 17172452]

26. Schuck P. Size-distribution analysis of macromolecules by sedimentation velocity ultracentrifugation and lamm equation modeling. Biophys J. 2000; 78:1606-1619. [PubMed: 10692345]

27. Burstein EA, Abornev SM, Reshetnyak YK. Decomposition of protein tryptophan fluorescence spectra into log-normal components. I. Decomposition algorithms. Biophys J. 2001; 81:1699_ 1709. [PubMed: 11509382]

28. Shen C, Menon R, Das D, Bansal N, Nahar N, Guduru N, Jaegle S, Peckham J, Reshetnyak YK. The protein fluorescence and structural toolkit: Database and programs for the analysis of protein fluorescence and structural data. Proteins. 2008; 71:1744-1754. [PubMed: 18175321]

29. Ionescu RM, Eftink MR. Global analysis of the acid-induced and urea-induced unfolding of staphylococcal nuclease and two of its variants. Biochemistry. 1997; 36:1129-1140. [PubMed: 9033404] 
30. Kelly SM, Price N. The use of Circular Dichroism in the investigation of protein structure and function. Current Protein and Peptide Letters. 2000; 1:349-384.

31. Nicol F, Nir S, Szoka FC Jr. Orientation of the pore-forming peptide GALA in POPC vesicles determined by a BODIPY-avidin/biotin binding assay. Biophys J. 1999; 76:2121-2141. [PubMed: 10096907] 

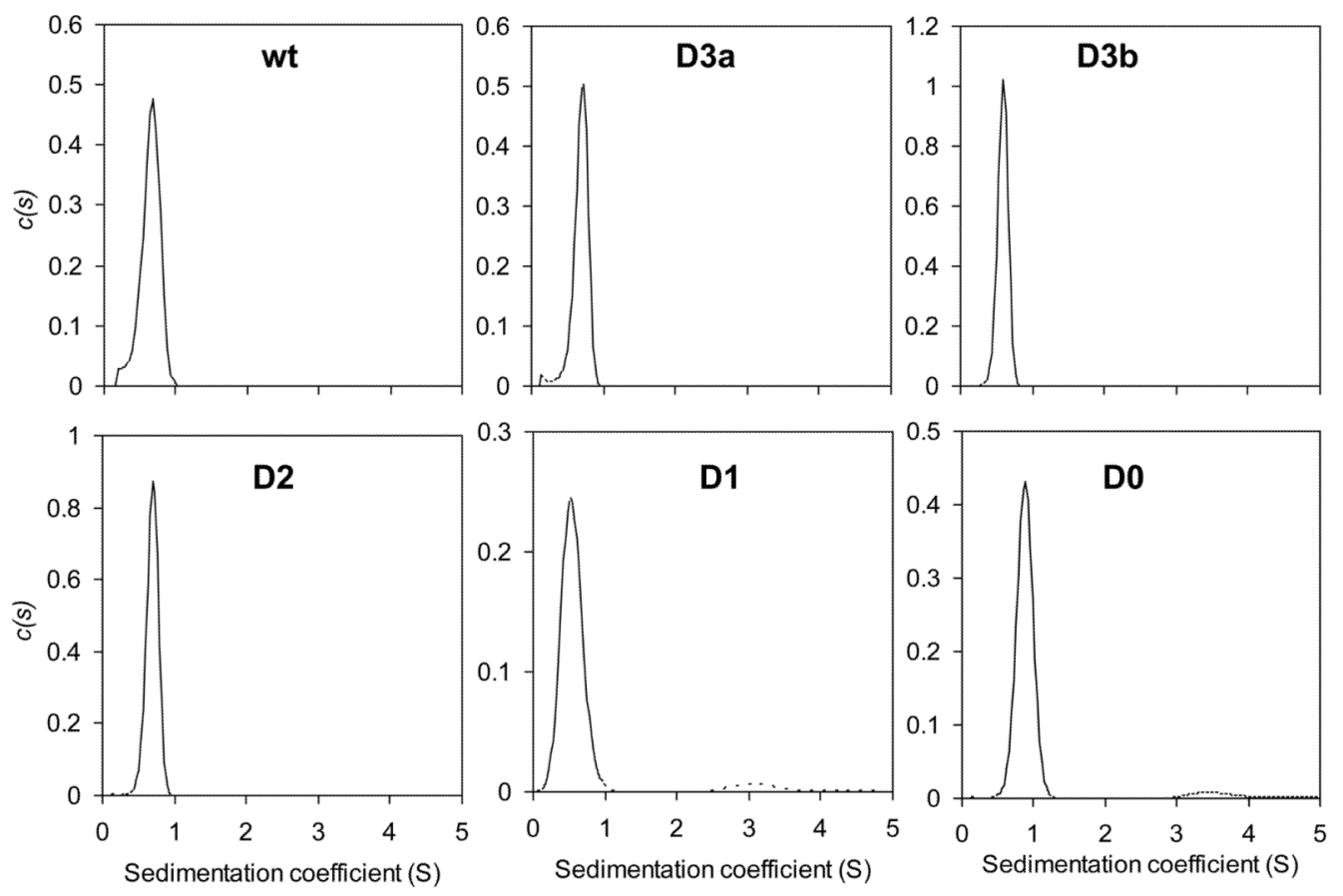

Figure 1. Sedimentation velocities of the peptide variants

The apparent sedimentation coefficient distribution is shown, as derived from sedimentation velocity profiles of the peptides in $5 \mathrm{mM}$ phosphate buffer, $\mathrm{pH} 8$, at $7 \mu \mathrm{M}$. 

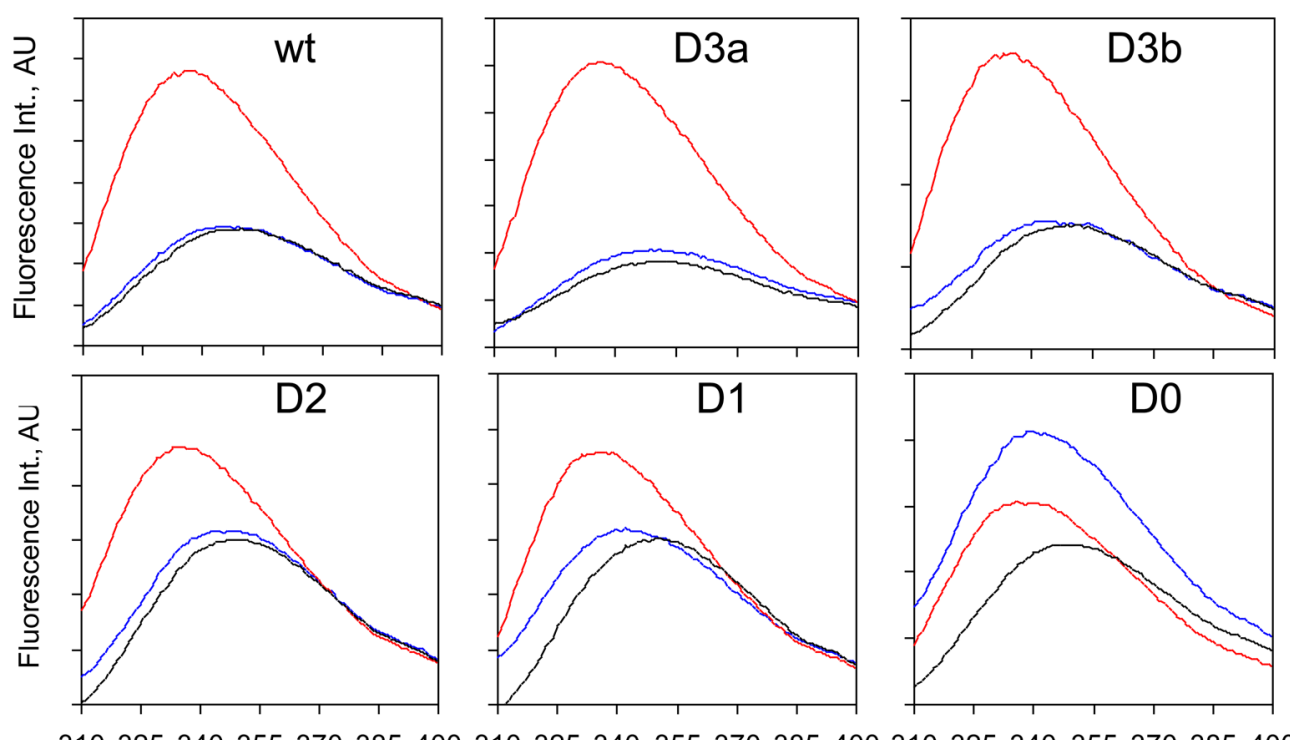

Wavelength, $\mathrm{nm}$

Wavelength, nm

Wavelength, $\mathrm{nm}$

Figure 2. Fluorescence spectra of peptides in buffer and with POPC vesicles

Emission spectra of each variant were recorded under the following conditions: buffer at $\mathrm{pH}$ 7.5 (black lines), POPC at neutral pH (blue lines), and POPC $\mathrm{pH} 4$ (red lines). The $\mathrm{pH}$ values for the different POPC samples at neutral $\mathrm{pH}$ were selected according to the midpoint and slope of the transitions shown in Fig. 6: wt, $\mathrm{pH} 7.5$; D3a, $\mathrm{pH} 7.5$; D3b, pH 7.1; D2, pH 6.5; D1, pH 6.2; D0, $\mathrm{pH}$ 8. Peptide concentration was $1.5 \mu \mathrm{M}$, and the lipid concentration $375 \mu \mathrm{M}$. Fluorescence intensity is given in arbitrary units (A.U.). 

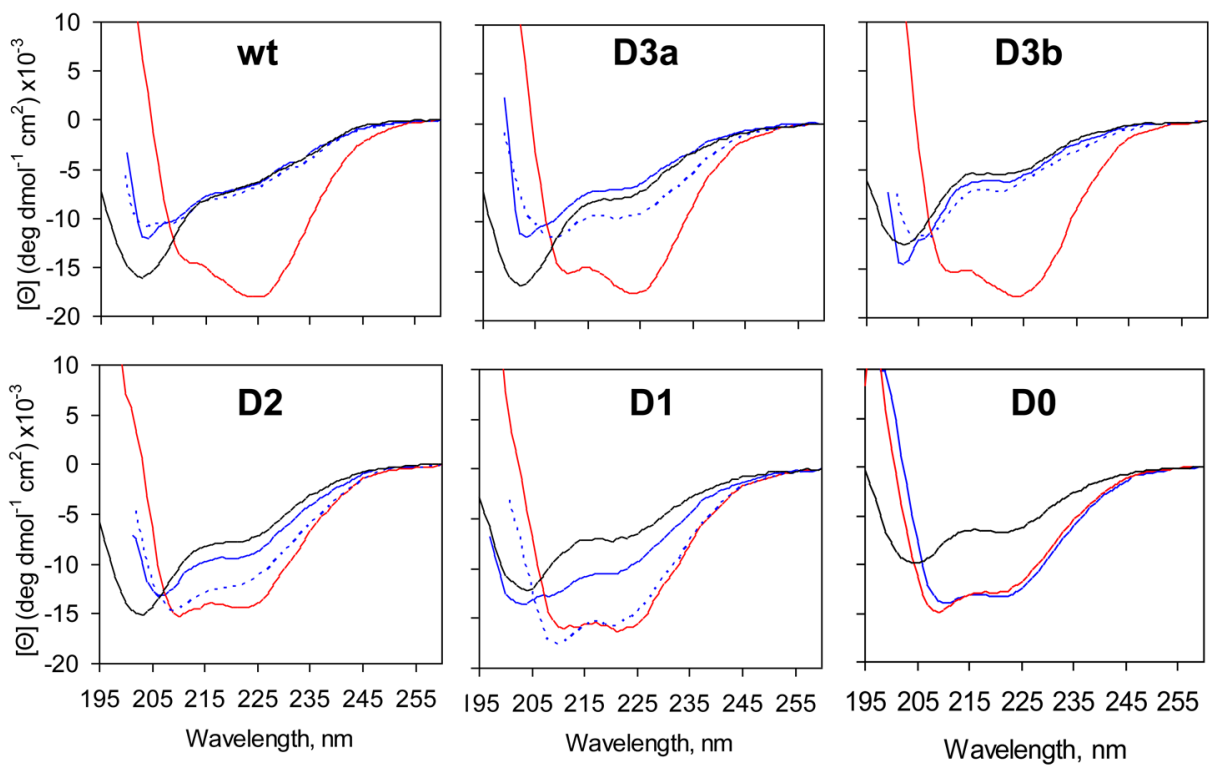

Figure 3. Circular dichroism of peptides in buffer and with POPC vesicles

Far-UV CD spectra were recorded for all variants under different conditions: buffer $\mathrm{pH} 7.5$ (black lines), POPC pH 7.4 (blue lines), and POPC pH 4 (red lines). The reversibility of the insertion process was studied by raising the $\mathrm{pH}$ of samples at $\mathrm{pH} 4$ (dashed blue line) to 7.4. Reversibility for D0 was not studied, as the ellipticity changes between the states at $\mathrm{pH} 7.5$ and 4 were negligible. In all samples, the final peptide and lipid concentrations were $5 \mu \mathrm{M}$ and $1.5 \mathrm{mM}$, respectively. 

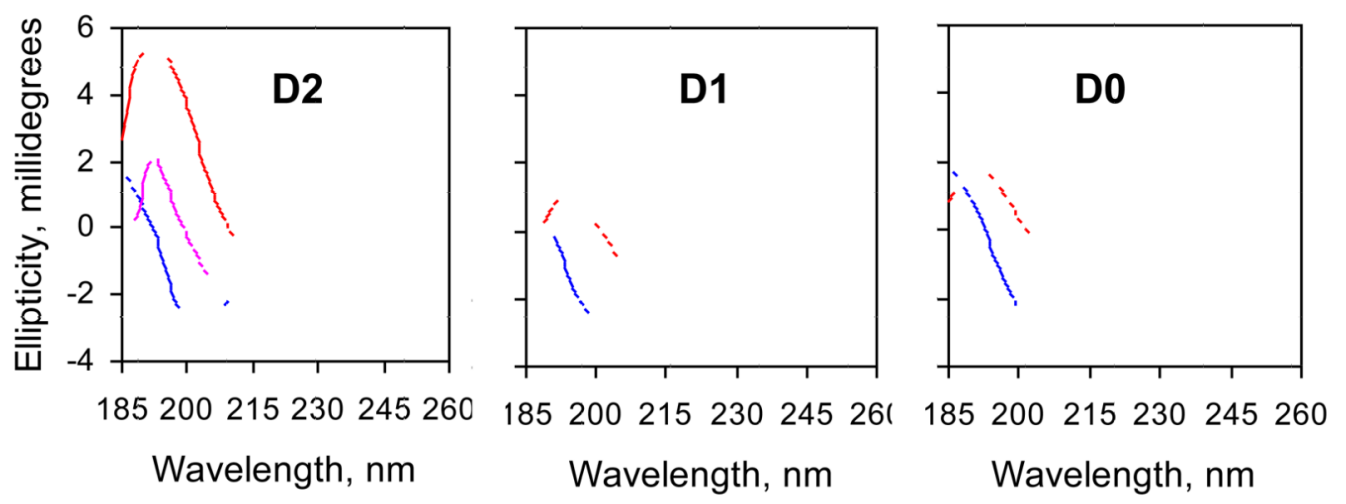

Figure 4. Oriented circular dichroism

OCD spectra of D2, D1 and D0 measured on oriented POPC supported bilayers at neutral (blue lines) and acid (red lines) pHs. The OCD spectrum of D2 at pH 1.9 was also recorded (purple line). The experimental spectra are corrected for the lipid background. 

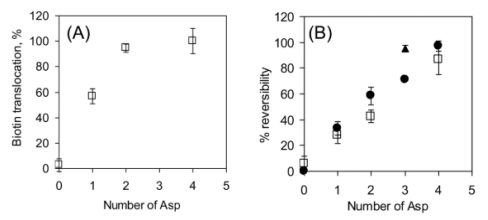

Figure 5. Quantification of the membrane insertion (biotin translocation) and reversibility Data corresponding to the biotin translocation assay (open squares) and CD (black symbols) were plotted against the number of Asp residues in the TM and C-terminal regions. (A) Degree of normalized biotin translocation (open squares). For data normalization, the translocation level of wt pHLIP labeled with biotin at the $\mathrm{C}$ - and N-terminus were used as $100 \%$ and $0 \%$, respectively. Results from D3a and D3b are not shown for the biotin translocation assay, as the biotin labeling for these peptides affected the interaction with lipids (data not shown). No adverse effects of the labeling were observed for the rest of the peptides tested. The averages and standard deviations are shown. (B) The percentage of reversibility of biotin translocation of the samples used in (A) is shown (open squares). For CD experiments (Fig. 5), the degree of reversibility was determined monitoring the relative changes in ellipticity at $222 \mathrm{~nm}$ (black symbols). The averages and the standard deviations are shown. Data corresponding to D3b appears as a triangle, while the rest of the CD data appear as circles. All data points were used for a linear fitting $\left(R^{2}=0.95\right)$. 

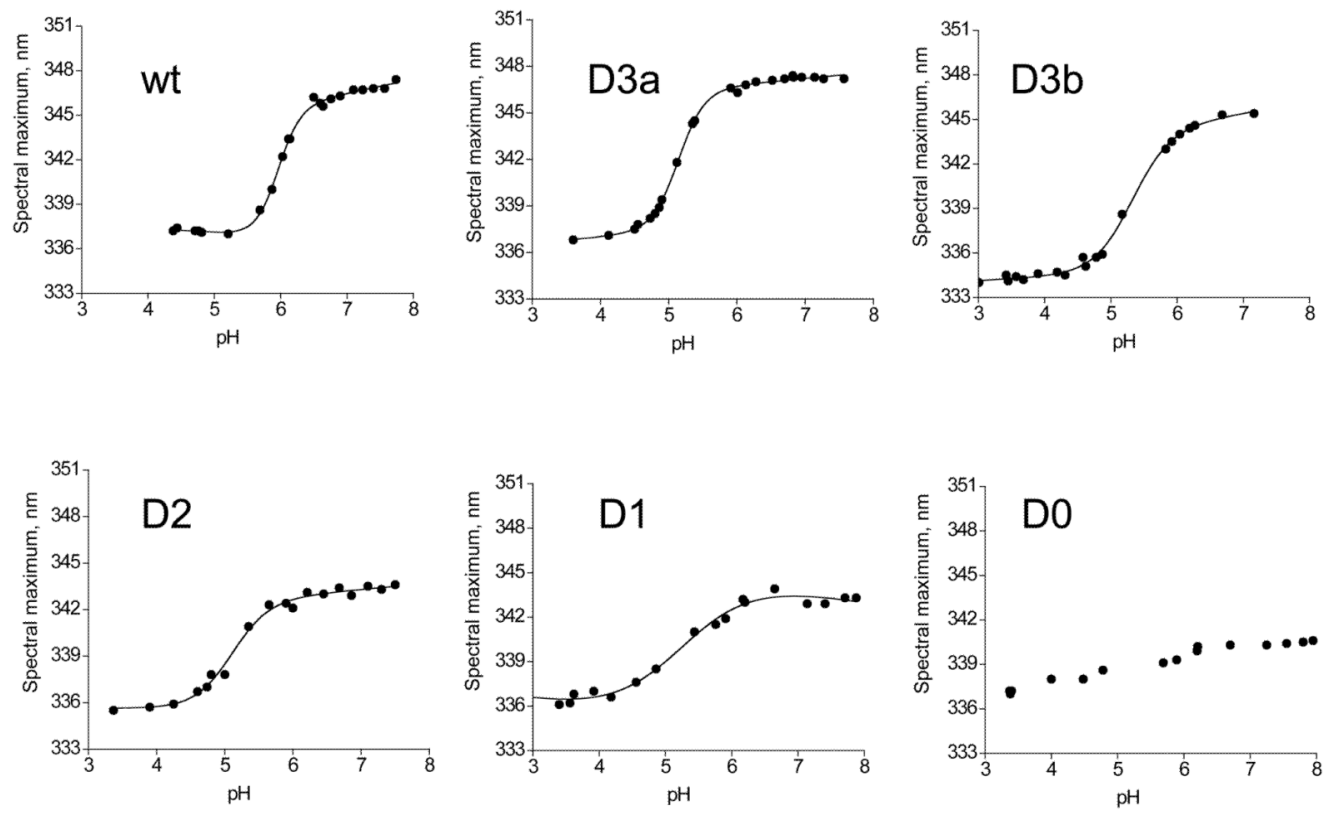

Figure 6. Fluorescence spectral maximum changes upon pH titration

The $\mathrm{pH}$-controlled transitions of the peptides in POPC were followed by monitoring the variations in the spectral maxima. The experimental data for the different peptides were fitted to Equation 1 (black lines). Representative experiments are shown. 

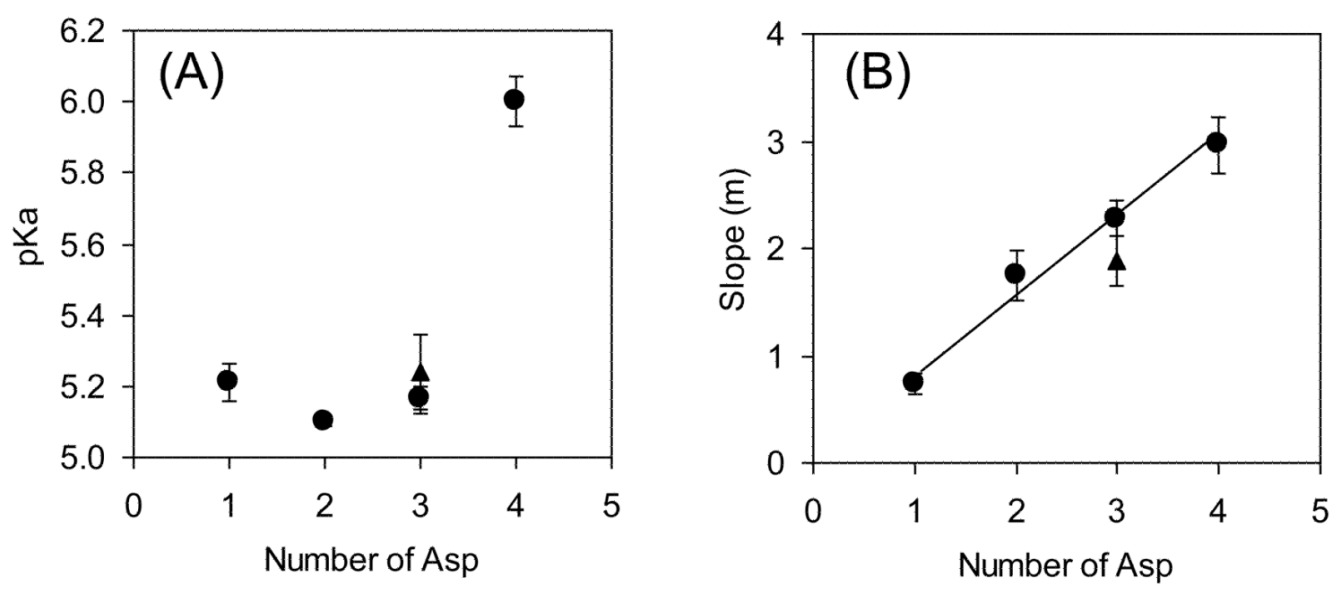

Figure 7. Parameters obtained from the fitting of the fluorescence pH transitions

The pKa (A) and m parameter (B) values obtained from the fitting of the data in Fig. 6 to Equation 1 are shown in black symbols. Data from the D3b variant are shown as triangles (to maintain the representation as in Fig. 5). The line corresponds to the fitting of all data points $\left(\mathrm{R}^{2}=0.93\right)$. Averages and standard deviations are shown. 


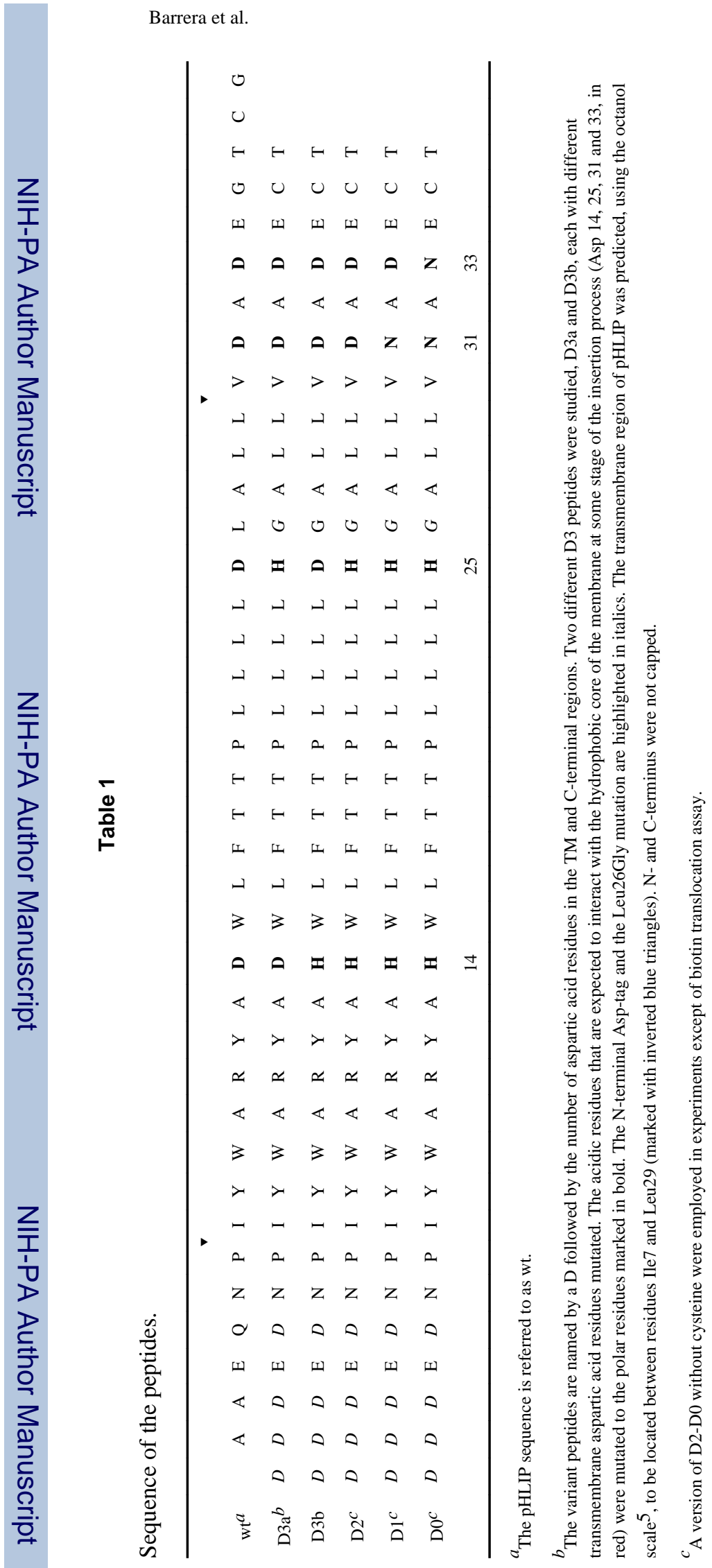

J Mol Biol. Author manuscript; available in PMC 2012 October 21. 
